\title{
CLADDING TO SUSTAIN CORROSION, CREEP AND GROWTH AT HIGH BURN-UPS
}

\author{
GUNNAR WIKMARK $^{1 *}$, LARS HALLSTADIUS ${ }^{2}$ and KEN YUEH ${ }^{1}$ \\ ${ }^{1}$ Westinghouse Electric Co. 5801 Bluff Rd, Columbia, SC 29250, USA \\ ${ }^{2}$ Westinghouse Electric Sweden AB \\ "Corresponding author. E-mail : wikmarg@westinghouse.se
}

Received January 31, 2009

Accepted for Publication February 20, 2009

The increasing power and other demands on PWR fuel is leading to a demand for cladding that has low corrosion but that should also be robust with regard to mechanical behavior, impact of the irradiation environment and the coolant chemistry. The Optimized ZIRLO $^{\mathrm{TM}}$ cladding is an evolutionary development of ZIRLO ${ }^{\mathrm{TM}}$ taking advantage of the long experience of the ZIRLO cladding but has significantly improved corrosion behavior. Recently, operation of Optimized ZIRLO to above $73 \mathrm{kWd} / \mathrm{kgU}$ has shown a reduction of the corrosion of almost $50 \%$.

KEYWORDS : Cladding, High Burn-up, Corrosion, Zr Alloys, Creep, Rod Growth

\section{INTRODUCTION}

The nuclear power plant utilities around the world are increasing the power output and minimizing the time off the grid when adjusting to the competitive electric power market. Up-rating of nuclear power plants is today becoming increasingly popular as a means to have a higher power production with, at least for smaller up-rates, limited investments and hence improved competitive edge. A higher power will increase the average heat flux and linear heat generation, LHR, and will in most cases also lead to higher peaking factors, that is, higher relative LHR for the highest power rods.

18-month cycles are today common for U.S. PWRs in order to minimize the time off the grid. A similar trend to longer cycles is seen also in Europe today. In the past several years, European plants have also begun aiming for high fuel burn-ups. One important reason for this has been to minimize the back-end cost per produced $\mathrm{kWh}$. The combination of a long cycle and efficient fuel use is also pushing the burn-ups to higher levels.

The longer cycles and the power up-rates have necessitated higher boron concentrations to control the additional reactivity. The combination of high LHR, long exposure in core, higher lithium concentration and more local boiling is challenging the cladding material. Optimized creep and growth properties, as well as corrosion properties, especially in more demanding water chemistry and enhanced metal-oxide interface temperatures, are very important for the successful operation in the more challenging conditions evolving today.

\section{CLADDING EVOLUTION}

ZIRLO $^{\mathrm{TM}}$ cladding ${ }^{1}$ material has replaced Zircaloy-4 in almost all of Westinghouse fuel deliveries since the introduction in the 1990's. More than six million ZIRLO cladding fuel rods have been delivered and operated in nuclear power plants in the U.S.A., Europe and Asia.

The ZIRLO cladding was developed to have improved or equal properties relative to Zircaloy-4 in all important aspects. Growth, creep and corrosion - especially in an elevated lithium environment - are properties limiting the fuel operation in the more demanding conditions and were of particular importance in the development of ZIRLO. The vast operational experience with ZIRLO cladding, [1] has shown the ZIRLO cladding to be superior to Zircaloy4 in these important aspects and also having consistent properties within the manufacturing process variability. ZIRLO cladding has also been shown to be very robust to water chemistry impact, such as operation in coolant with elevated lithium [2].

As the LHR and heat flux is increasing the corrosion, the properties of the cladding are becoming more and more challenged. Most plants are still operating at moderate temperatures, but if a higher heat flux and even boiling is experienced, the resulting elevated metal-cladding interface temperature could lead to accelerated corrosion. Today,

\footnotetext{
${ }^{1}$ ZIRLO is a trademark of Westinghouse Electric Company LLC
} 
some plants are operating with a Modified Fuel Duty Index [3], MFDI, a measure of the relative corrosion impact from the plant operation, of more than 800 . This value is almost twice as high as a typical value for an arbitrary PWR rod even today.

To obtain more margin with regard to corrosion and consequently allow high burn-ups in high duty plants, a new cladding material has been developed. The purpose has been to build upon the extensive experience of the ZIRLO cladding. The reason for this is that the ZIRLO cladding has been showing a good robustness and manufacturing consistency. The new alloy has been developed to retaining the many good ZIRLO properties but improving the corrosion behavior.

It is well known that the tin content will have an impact on the corrosion behavior and that the lowered tin contents in ZIRLO relative to Zircaloy-4, with approximately 1.3\% even in low tin ingots, is one reason for the improved corrosion properties of ZIRLO, with around $1 \%$ tin.

By lowering the tin contents further, the alloy Optimized ZIRLO has been obtained. This alloy is hence an evolutionary alloy derived from ZIRLO and relies on the robustness and experience of this alloy with regard to operation and manufacturing.

Some of the development and experience of the manufacturing and irradiation of Optimized ZIRLO has been reported earlier $[1,4,5]$. This paper reports on the most recent results, where a burn-up of above $70 \mathrm{MWd} / \mathrm{kgU}$ has been obtained.

\section{OPTIMIZED ZIRLO}

The Optimized ZIRLO has been developed from
ZIRLO by lowering the tin contents and by changing the processing [7]. The tin contents is in the range 0.6 to 0.8 $\%$ while the other alloying elements, such as niobium and iron, are kept at the same level as in ZIRLO, i.e. nominally $1.0 \%$ and $0.1 \%$, respectively. The lowered tin content also affects the mechanical properties and the out-of-reactor and in-reactor creep behavior. The material will have a higher creep rate, an impact that if not compensated for will lower the margins for use as fuel cladding. By adjusting the processing, i.e. the intermediate and final anneals in the cladding tube manufacturing, the creep rate can be lowered. This will, however, affect the tensile strength. Such a lowered tensile strength is only of consideration during the first few months in core since irradiation hardening due to fast neutron impact will enhance the tensile strength of the material. Optimized ZIRLO is delivered in partially recrystallized state, PRXA, with optimized properties with regard to the combination of creep and mechanical properties.

\section{PROPERTIES AND EXPERIENCE OF OPTIMIZED ZIRLO}

\subsection{Corrosion}

Optimized ZIRLO is or has been used as cladding or structure material in 14 reactors all over the world. The most recent results have been gathered by operation for four 18-months cycles where the maximum rod burn-up was over $73 \mathrm{MWd} / \mathrm{kgU}$. In addition, additional records have been collected at lower burn-ups, confirming the low and consistent corrosion rate of Optimized ZIRLO, not only relative to Zircaloy-4, but also ZIRLO, as shown in Fig. 1.

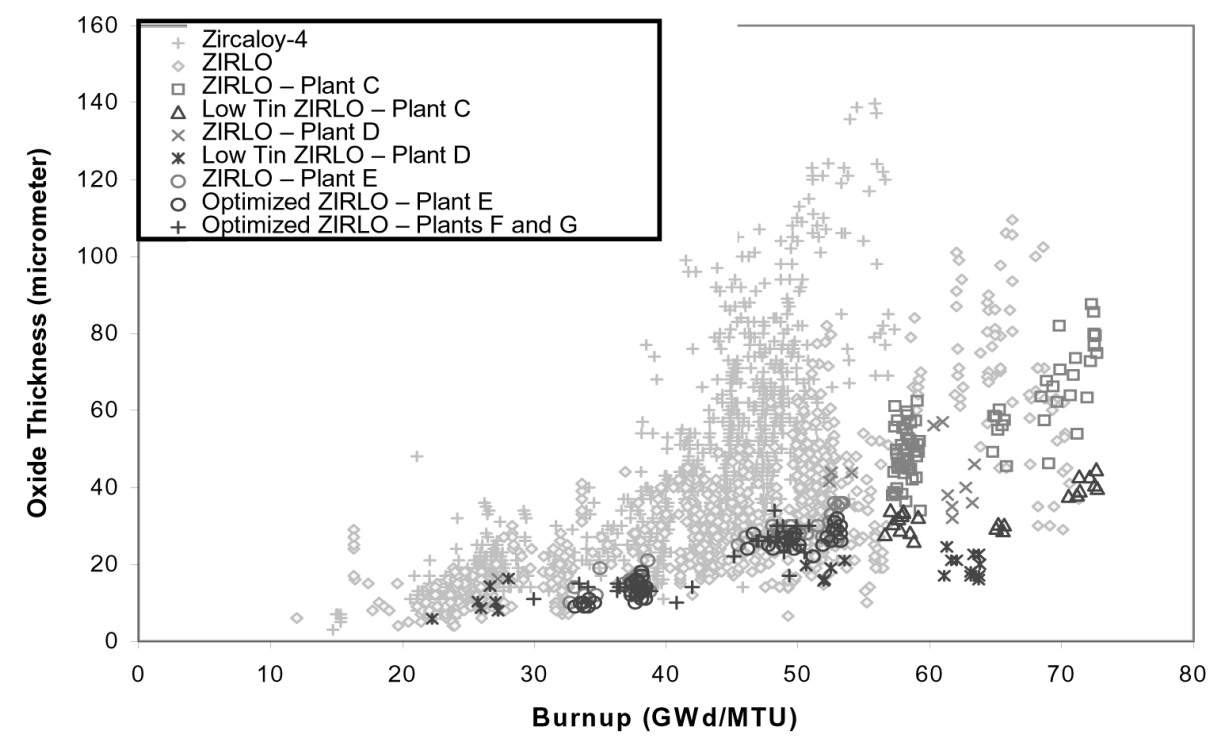

Fig. 1. Oxide Thickness vs, Burn-Up Recorded for Optimized ZIRLO 


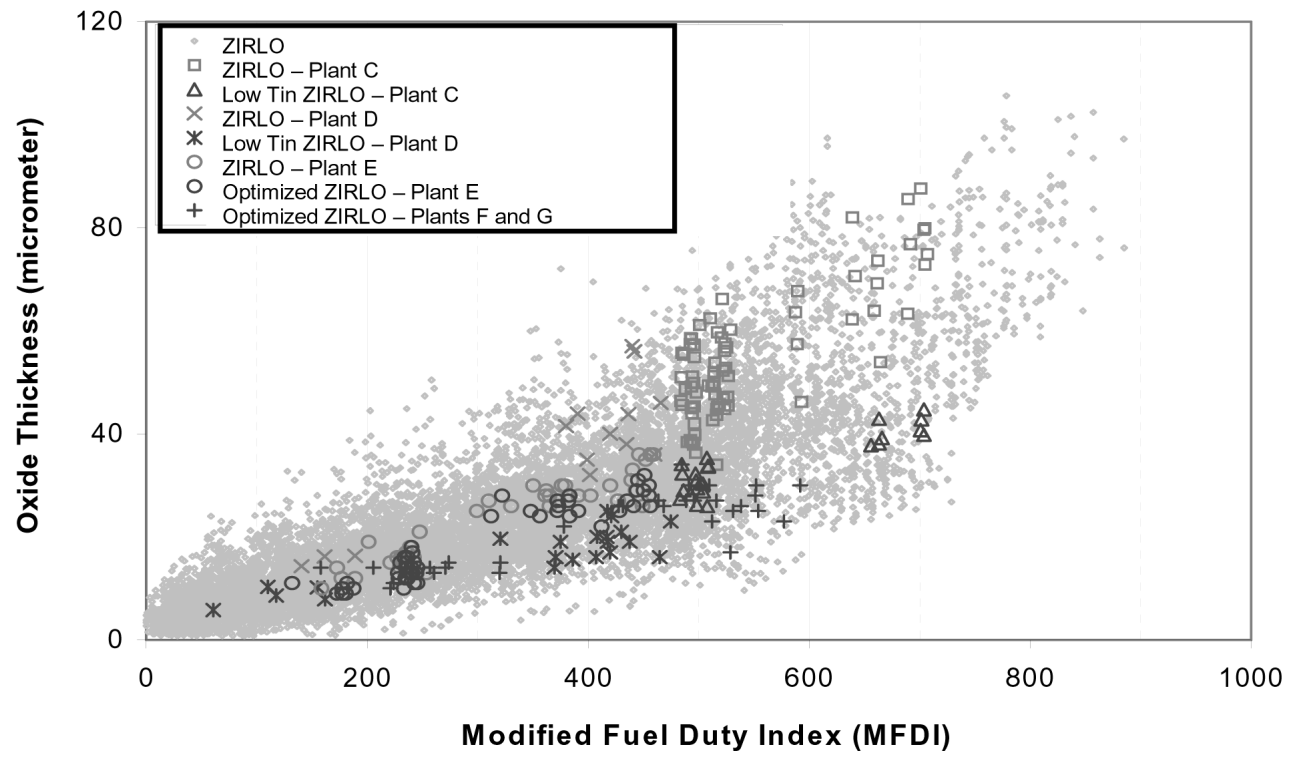

Fig. 2. Oxide Thickness vs, Modified Fuel Duty Index (MFDI) for ZIRLO, Low Tin ZIRLO and Optimized ZIRLO

The oxide thickness is significantly lower for Optimized ZIRLO even when compared to ZIRLO. This is especially significant at higher burn-ups, above approximately 50 $\mathrm{MWd} / \mathrm{kgU}$, corresponding to approximately 30 microns oxide thickness, where corrosion acceleration by thermal feed-back of a thick oxide film and hydrogen rim impact seems to be absent for Optimized ZIRLO. Low tin ZIRLO in Fig. 1 refers to a cladding material with similar tin contents as Optimized ZIRLO but with a stress relieved microstructure as for ZIRLO. This results in equal corrosion properties as Optimized ZIRLO but slightly different mechanical properties and creep properties [7].

The correlation between oxide thickness and the burnup is not always simple since the corrosion acceleration is not only a matter of burn-up but also of the power history. Leech and co-workers have developed a method to compare oxide thickness recorded on rods from plants with different duties. They defined a Modified Fuel Duty Index, MFDI [5]. The MFDI is expressed as follows.

$$
\mathrm{MFDI}=\Delta \mathrm{T} * \mathrm{t}+\mathrm{b} * \mathrm{M}_{\mathrm{t}}
$$

where $\Delta \mathrm{T}$ is the oxide layer surface temperature above 304.4 C, t the time, b a constant and $\mathrm{M}_{\mathrm{t}}$ the total mass evaporation. Using the MFDI instead of the burn-up a more consistent picture is obtained, see Fig. 2.

The limited corrosion acceleration exhibited by Optimized ZIRLO despite a high MFDI, implying a high heat flux and considerable sub-nucleate boiling, is showing the robustness of the Optimized ZIRLO material with regard to corrosion. No acceleration is discerned for
Optimized ZIRLO in either of the correlations with burnup or MFDI, respectively.

Another factor that may cause acceleration of the oxide growth, in addition to the thermal feed-back and of the hydride rim, is the presence of lithium. ZIRLO has been shown [2] to operate successfully in a higher duty plant in maximum lithium concentration up to $6 \mathrm{ppm}$ and a very high value of ppm-days above 3.5 ppm during 18month cycles. Lowering the tin contents will be detrimental to the corrosion resistance in lithiated aqueous environments for most alloys, both in autoclaves and in test reactors, but only when the tin contents is below $0.5 \%[8,9]$. Consequently, in autoclave tests, in up to $70 \mathrm{ppm}$ lithium in water at $360 \mathrm{C}$, Optimized ZIRLO has been shown to perform even better than ZIRLO with approximately 30\% lower oxide growth after 250 days. Optimized ZIRLO has obviously sufficiently high tin contents to provide resistance to elevated lithium and yet still benefit from its improved corrosion properties relative to ZIRLO also with regard to water chemistry impact.

\subsection{Growth}

The improved corrosion behavior is also shown in the performance of spacer grids. The thin material makes the grids prone to exhibit growth from hydrogen pick-up due to corrosion in addition to the growth from the fast neutron fluence. Optimized ZIRLO will hence experience less growth due to the lower corrosion and resulting lower hydrogen pick-up, as illustrated in Fig. 3

A lower spacer grid growth provides extra margin to grid-to-rod fretting by minimizing or eliminating the potential gap between the grid contact points and the fuel rod.

The irradiation growth is in itself considerably lower 


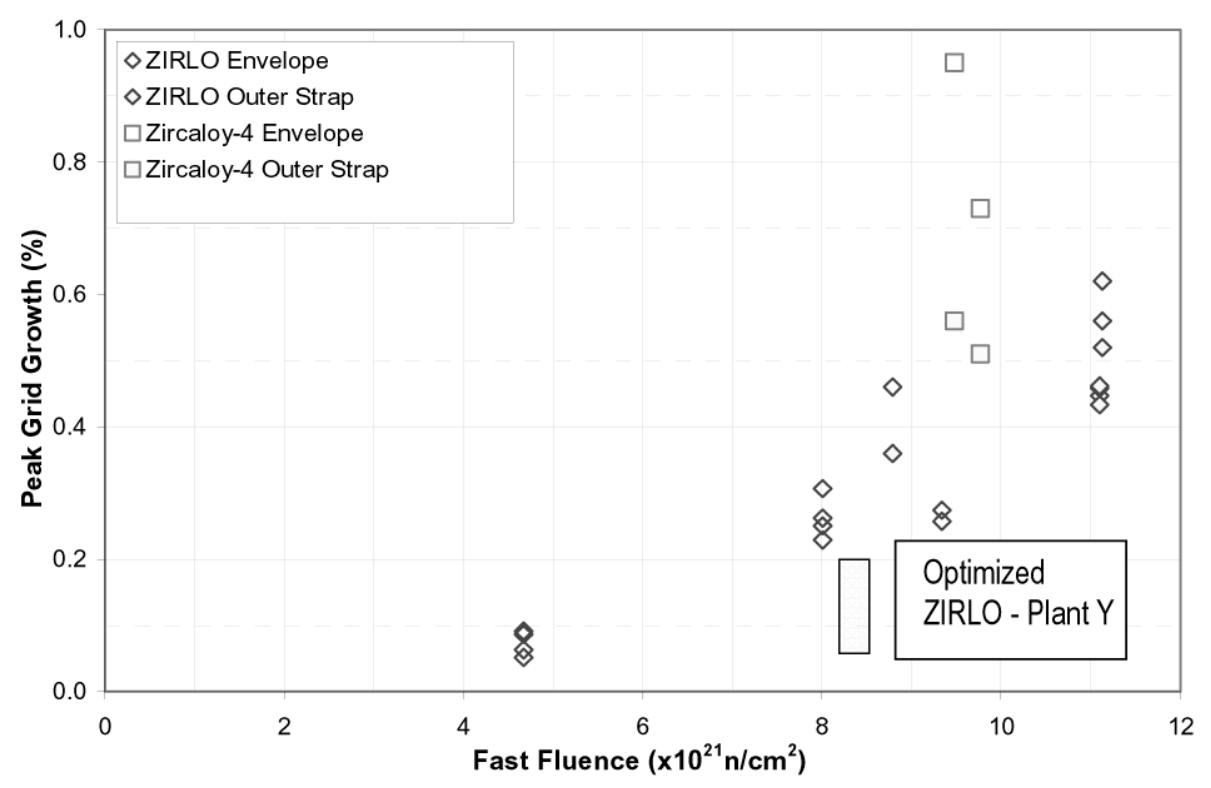

Fig. 3. ZIRLO and Optimized ZIRLO Spacer Grid Growth Comparison

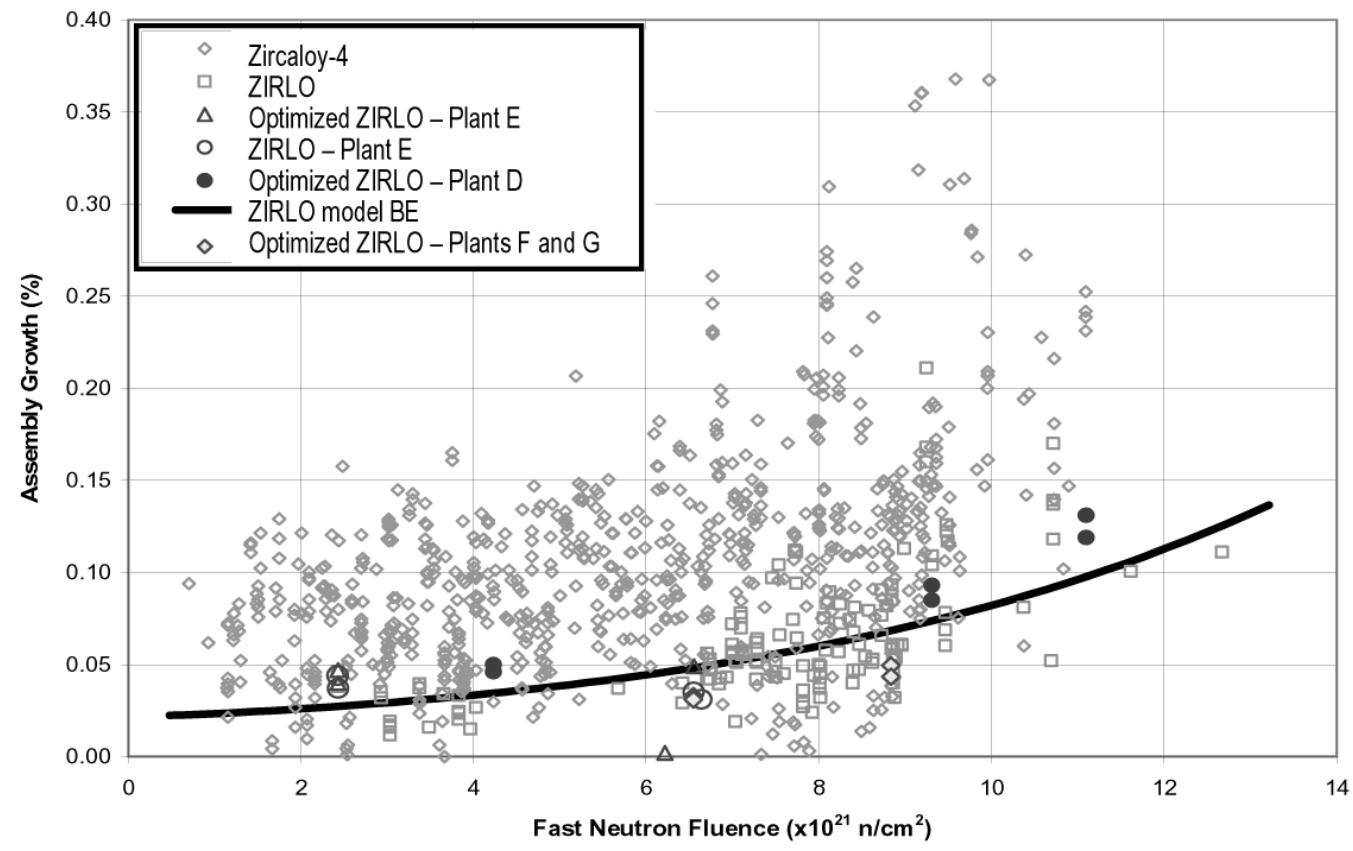

Fig. 4. Fuel Assembly Growth with Optimized ZIRLO or ZIRLO Guide Tubes

for ZIRLO and Optimized ZIRLO than for Zírcaloy-4. This is one of the properties where the evolutionary development of Optimized ZIRLO from ZIRLO is resulting in very similar behavior, as shown in Fig. 4.

A test performed in an in-reactor test assembly in a commercial PWR [7, 4] has shown that the free growth of Optimized ZIRLO actually is marginally lower than for ZIRLO.

The impact of growth on real fuel rods is not significantly affected by the cladding material as long as the hydrogen level is low [9] and the creep properties are similar, leading to the main growth driven by pellet- 


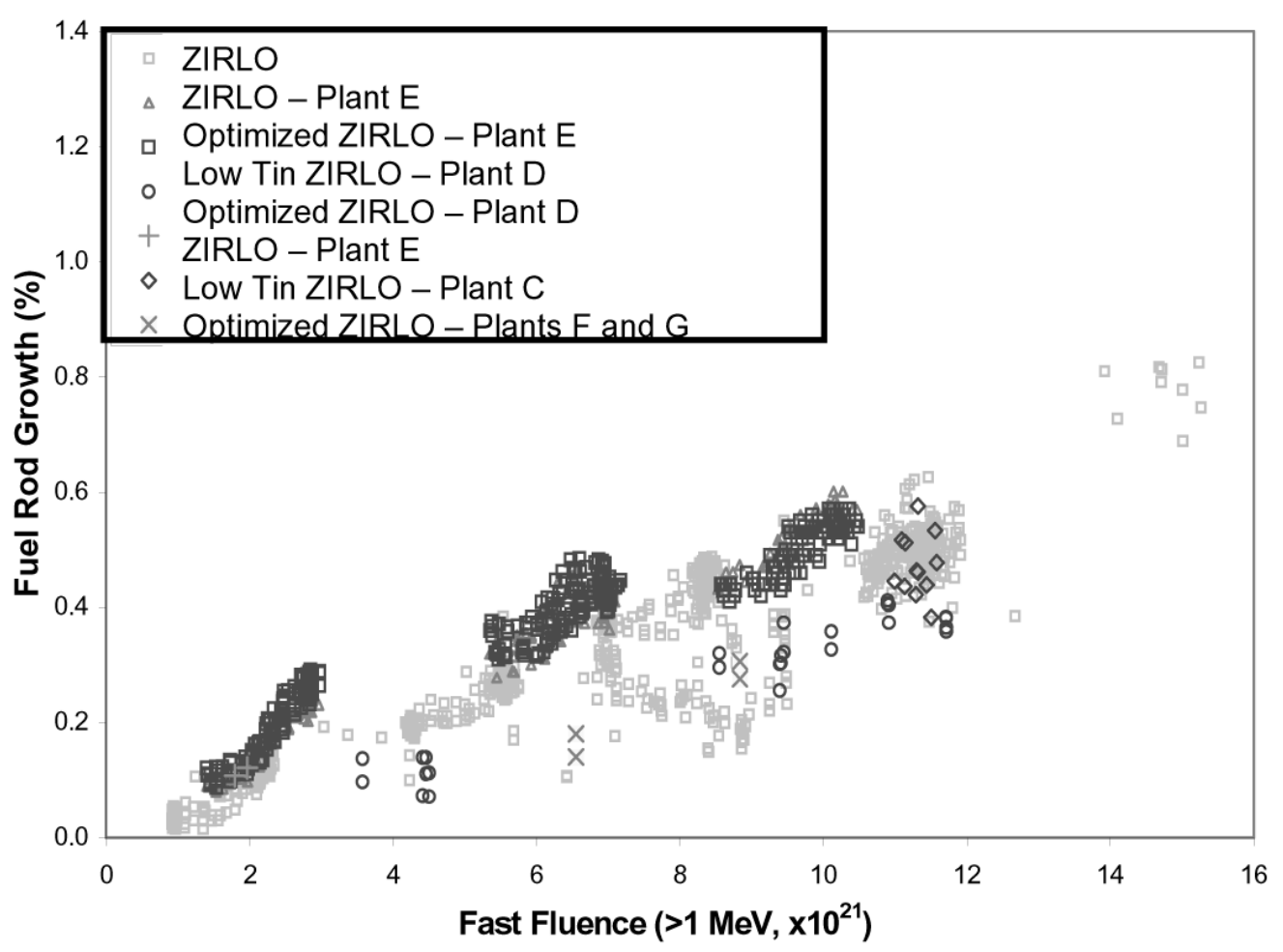

Fig. 5. Rod Growth of Optimized ZIRLO

cladding contact. The rod growth is consequently found to be similar for Optimized ZIRLO and ZIRLO, see Fig. 5.

\subsection{Creep}

It has been observed that a lower tin contents in itself will increase the creep rate of an alloy [6,7] The optimization of the processing has hence been made to compensate for the higher creep inherently resulting from the lower tin contents of Optimized ZIRLO. The main adjustment has been to the final heat-treatment during tube manufacturing, which is resulting in a partially re-crystallized microstructure. The creep behavior of Optimized ZIRLO is consequently very similar to that of ZIRLO. This has also been shown by the in-reactor creep and growth tests $[7,4]$ discussed earlier where the creep measured for Optimized ZIRLO is found to be equal to that of ZIRLO after one and two cycles in core, corresponding to a burnup of up to above $40 \mathrm{kWd} / \mathrm{kgU}$.

\section{APPLICATION OF OPTIMIZED ZIRLO}

Optimized ZIRLO has already been licensed in the U.S.A. Licensing efforts are currently ongoing in a number of other countries. Optimized ZIRLO deployment has started with region reloads delivered to two plants in the U.S.A. in 2008.

\section{SUMMARY AND CONCLUSIONS}

Optimized ZIRLO has equally good growth and creep properties as ZIRLO, but has significantly improved corrosion properties.

Recently, operation of rods up to above $73 \mathrm{MWd} / \mathrm{kgU}$ has shown that the improved properties with regard to corrosion are consistent also at such high burn-ups. Optimized ZIRLO has been licensed in the U.S.A. and reloads has been delivered to two plants in 2008 .

\section{REFERENCES}

[ 1 ] R.P. Knott, R.L. Kesterson, L.G. Hallstadius, M.Y. Young, ENS/Top Fuel, Wurzburg, Germany, March 16-19, 2003, Paper 302

[2 ] K. Kargol, J. Stevens, J. Bosma, J. Iyer, G. Wikmark, Proc. Int'l Fuel Performance Meeting, San Francisco, CA, September 30 - October 3, 2007, Paper 1099

[ 3 ] W.J. Leech and K. Yueh, Proc. ENS/Top Fuel, Stockholm, Sweden, May 27-30, 2001, Paper P2-16

[ 4 ] L. Hallstadius, R. Kesterson, H. Shah, J. Foster, D. Colburn, Proc. 15th Int'1 Conf. Nucl. Eng. (ICONE15), Nagoya, Japan, April 22-26, 2007, Paper 10645

[ 5 ] R. Kesterson, K. Yueh, H. Shah, J.P. Foster, D. Colburn, L. Hallstadius, I. Arana, Proc. 2006 Int'l Meeting LWR Fuel Perf. (Top Fuel 2006), Salamanca, Spain 2006, p. 67-71

[6] W.A. McInteer, D.L. Baty, K. O. Stein, $8^{\text {th }}$ Symp., ASTM STP 1023, p. 621-640 (1989) 
[ 7 ] J. Foster, K. Yueh, R. J. Comstock, 15th Int'1 Symp Zirc, Nucl. Ind., Sunriver, OR, June 24-28, 2007

[ 8 ] G. Sabol et al, Zirc. Nucl. Industry, $8^{\text {th }}$ Symp., ASTM STP 1023 , p. 227-245 (1989)

[9] F. Garzarolli, R. Manzel, R.S. Reynolds, Proc. ANS Light
Water Reactor Fuel Perf. Conf., Park City, UT, April 1013,2000

[10] R.L.Kestersen, S.J. King, R.J. Comstock, Proc. Light Water Reactor Fuel Perf. Conf., Park City, UT, USA, April 1013,2000 